\title{
Modification of the Physical Properties of Alginate with the Addition of Polymannuronate and Polyguluronate
}

\author{
Subaryono* and Suryanti \\ Research Centre for Marine and Fisheries Product Processing and Biotechnology, Jakarta, Indonesia
}

\begin{abstract}
Modification the physical properties of alginate using polymannuronate and polyfuluronate has been conducted. Polimannuronate and poliguluronate isolated from alginate with hidrochloric acid heating methods and precipitation based on $\mathrm{pH}$, and the resulting product was characterized its viscosity. Polymannuronate and polyguluronate used to modify the functional properties of alginate from Sargassum crassifolium. Polymannuronate and polyguluronate were added and mixed into the alginate powder with a proportion of $0,10,20$ and $30 \%(w / w)$. The results were then characterized the nature of the gel formulations which include gel strength, modulus of rigidity and syneresis. The results showed that the viscosity of the alginate used as a source polymanuronate and polguluronate of $162.89+3.66 \mathrm{cP}$. Polymannuronate and polyguluronate product has a viscosity respectively $85.00 \pm 5.90 \mathrm{cP}$ and $100.44 \pm 2.27 \mathrm{cP}$. The addition of polymannuronate and polyguluronate into alginate produced the characteristic changes of the gel. The addition of polyguluronat tended to improve gel strength and modulus of rigidity, while the addition of polymannuronate tended to lower the gel strength with the same modulus of rigidity of alginate gel.
\end{abstract}

\section{Introduction}

Alginate is one type of hydrocolloid, which is a colloidal system by organic polymers in the
water. In Indonesia, the alginate can be extracted from brown seaweeds like Sargassum sp.
and Turbinaria sp., that the potential was quite large [1]. Alginate mostly utilized in the field
of food as an emulsion stabilizer in ice cream, suspending the chocolate milk, yoghurt and
viscosity regulators in others. In the field of non-food, alginate is widely used as a thickener
in textile printing, regulatory uniformity and surface smoothness of paper, controlling
penetration and stability of glue made of starch and latex, and regulators slow release of
chemicals in fertilizers and pharmaceuticals [2].
Functional properties of natural alginate often have weakness such as low solubility, low
gel strengths, as well as high value of syneresis so that cause limitations in its use [3]. Some
disadvantages of natural alginate such as poor solubility, unstability of the solution and
syneresis were associated with the presence of compounds guluronic acids, a chemical

* Corresponding author: yono_ipn@yahoo.co.id 
structure that easily bind with divalent or multivalent ions [4]. In particular for alginates extracted from Indonesian brown seaweed such as Sargassum sp. and Turbinaria sp., which has low mannuronic-guluronic ratio (MG ratio), causing the high value of syneresis on the gel [5]. One effort to overcome the weakness of natural alginate is to make modifications like adding polymannuronate and polyguluronate to fix these weaknesses. In this study we have evaluated the effects of adding polymannuronate and polyguluronate on the physical properties of the alginate gel.

The aims of this study was to modify the characteristics of alginate gel, using the addition of polymannuronate and polyguluronate to fix some of the weaknesses that exist in the natural properties of alginate gel.

\section{Materials and methods}

Alginate used in this study was extracted from Sargassum sp. derived from Binuangen waters, province of Banten, Indonesia. $\mathrm{CaCO}_{3}$ purchased from Merck Millipore Singapore. Glucono-delta laktone (GDL) purchased from China Qingdao Hongjin Chemical Co. Ltd.

Isolation of polymannuronate and polyguluronate performed according to the method of acid heating [6]. First of all, alginate was dissolved in $0.3 \mathrm{M} \mathrm{HCl}$ to make $5 \%$ alginate solution and heated on a hotplate for 5 hours. The solution was centrifuged at $6000 \mathrm{rpm}$ for 10 minutes and the precipitate was separated and resuspended in akuadest. The $\mathrm{pH}$ of solution was adjusted $5 \mathrm{M} \mathrm{NaOH}$ to obtain a $\mathrm{pH}$ of 2.8 and this $\mathrm{pH}$ was kept constant for 24 hours. The solution then centrifuged at $6,000 \mathrm{rpm}$ for 10 minutes. The filtrate which is a block of polymannuronate neutralized with $1 \mathrm{M} \mathrm{NaOH}$ and freeze dried to obtain polymannuronate. The precipitate which was a block polyguluronate neutralized with $1 \mathrm{M} \mathrm{NaOH}$ and freeze dried to get polygulronate. Furthermore, both polymannuronate and polyguluronate gained were ground to make a 60 mesh powder.

Modifications of alginate gel made by mixing alginate with polymannuronate or polyguluronate by percentage of polymannuronate or polyguluronate varied as $0,10,20$ and $30 \%$ of the alginate. Both mixtures were blended until homogeneous and using for gel preparation.

Gel preparation was done by dissolving $1 \%$ hydrocolloid in akuadest, and then $20 \mathrm{mM}$ $\mathrm{CaCO}_{3}$ was added and stirred until homogeneous. Recently added $30 \mathrm{mM}$ GDL to the mixture and stirred until homogenous. The mixture is then molded in a gel molding and stored at room temperature for 1 hour to form a solid gel. Characteristics of the gel was then measured with a TA_XT pluss texture analyzer. Parameters observed for the texture profile were gel strength and rigidity modulus. Gel strength is stated how many grams of load that can be retained by the gel until the gel is broken. While the rigidity modulus approached from the slope of the curve or gel strength values divided by the distance of $\mathrm{x}$-axis where the gel is broken. The higher value of the slope, the higher rigidity of the gel.

\section{Results and discussion}

Isolation of polymannuronate and polyguluronate from alginate was obtaining yield of polymannuronate $34.93 \pm 0.88 \%$ and polyguluronate $29.17 \pm 1.77 \%$. Physically polymannuronate obtained has a light beige color, while polyguluronate dark beige. Observations viscosity of alginate, polymannuronate and polyguluronate were presented in Table 1. From these data it appeared that polymannuronate and polyguluronate viscosity lower than the viscosity of alginate, suspected for a long alginate polymer higher. Because polymannuronate and polyguluronate isolated from alginate through chemically depolimarization, then the 
length of the polymer theoretically shorter than his native alginate. Therefore polymannuronate and polyguluronate viscosity smaller than its native alginate.

Table 1. The viscosity of alginate, polymannuronate and polyguluronate

\begin{tabular}{|c|c|}
\hline Sampel & Viskocity $(\mathbf{c P})$ \\
\hline alginate & $162.89 \pm 3.66$ \\
\hline polymannuronate & $85.00 \pm 5.90$ \\
\hline polyguluronate & $100.44 \pm 2.27$ \\
\hline
\end{tabular}

Note: values were expressed as mean \pm standard deviation

Texture profile of alginate gel modified with polymannuronate and polyguluronate shown in Figure 1. From the profile was seen that the addition of polymannuronate tend to reduce the strength of the alginate gel without altering the slope of the curve. This indicates the elasticity of alginate gel tends to remain despite the decline in the strength of the gel. The decline in the strength of this gel was caused by the ability of polymannuronate to bind $\mathrm{Ca}^{2+}$ ions is lower than polyguluronate, so the ability to form crosslinks between polymer is lower. The more polymannuronate in alginate resulting in the lower gel strength. This is consistent with previous studies in which the gel that produced from alginate with a high ratio MG (rich in polymannuronate) has a lower strength than the alginate rich in poliguluronate [5].

On the other hand, the profile of alginate gel modified with polyguluronate tend to increase the strength of the alginate gel with altering the slope of the curve. Increasing of the gel strenght is caused by the ability of polyguluronate to increase the ability in making Caalginat bridge between polymers. The slope of gel profile tend to increase, that mean there was increase in rigidity of the gel. This is consistent with previous studies showing that the rich poliguluronate alginate gel tends to produce a higher strength [5].

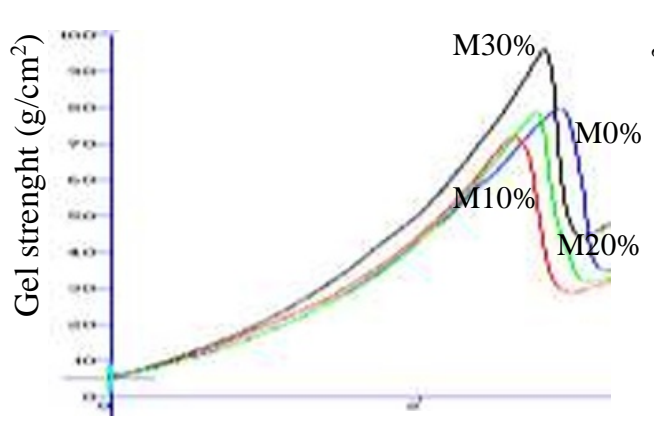

Distance mm

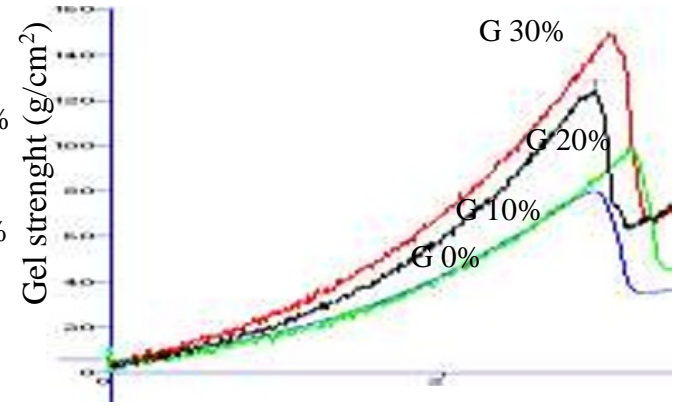

Distance mm

Fig. 1. Texture profile of alginate gel modified with polymannuronate (a) and polyguluronate (b), M: polymannurote $\mathrm{G}$ : polyguluronate

Alginate gel strength modified with polymannuronat and polyguluronat presented in Figure2. From these data it appears that the addition of the alginate polymannuronate reduce the strength of alginate gel. While the addition of polyguluronate improve gel strength alginate. Alginate with poly mannuronate adding, the gel strength was dropped from 84.67 $\mathrm{g} / \mathrm{cm}^{2}$ into $74.77 \mathrm{~g} / \mathrm{cm}^{2}$ at $10 \%$ polymannuronate addition and $79.87 \mathrm{~g} / \mathrm{cm}^{2}$ at $20 \%$ polymannuronate addition. while the addition of poly guluronic improve the gel strength from $84.67 \mathrm{~g} / \mathrm{cm}^{2}$ to $99.45 \mathrm{~g} / \mathrm{cm}^{2}$ on the addition polyguluronat $10 \%, 126.13 \mathrm{~g} / \mathrm{cm}^{2}$ on the 
addition of $20 \%$ and $148.3 \mathrm{~g} / \mathrm{cm}^{2}$ on the addition of $30 \%$ polyguluronate. The gel strength of alginate from this research were lower than that of alginate from Turbinaria decurens 261 $\mathrm{g} / \mathrm{cm}^{2}$ [14]. This is because the content of polygulurnate in alginate from Turbiaria decurens is higher than in alginate from Sargassum sp. Turbinaria decurens is reported to produce alginate with an mannuronate-guluronate ratio (M / G ratio) 0.72, lower than Sargassum sp. alginate 0.92 [14].

Improvement of alginate gel streng with the addition of polyguluronate was caused by increasing capacity in binding with $\mathrm{Ca}^{+}$. The higher content of guluronic blocks in alginate, the higher the possibility of binding $\mathrm{Ca}_{2}{ }^{+}$by their egg-box model of poliguluronat to produce crosslinking between alginate molecules [7]. The greater the number of complex crosslinking resulting from $\mathrm{Ca}^{2+}$ and egg-box models poliguluronat, the stronger the resulting gel. Some researchers have previously stated that high content of poliguluronat in alginate will produce stronger gel with more rigid texture $[8 ; 4 ; 10 ; 11]$.
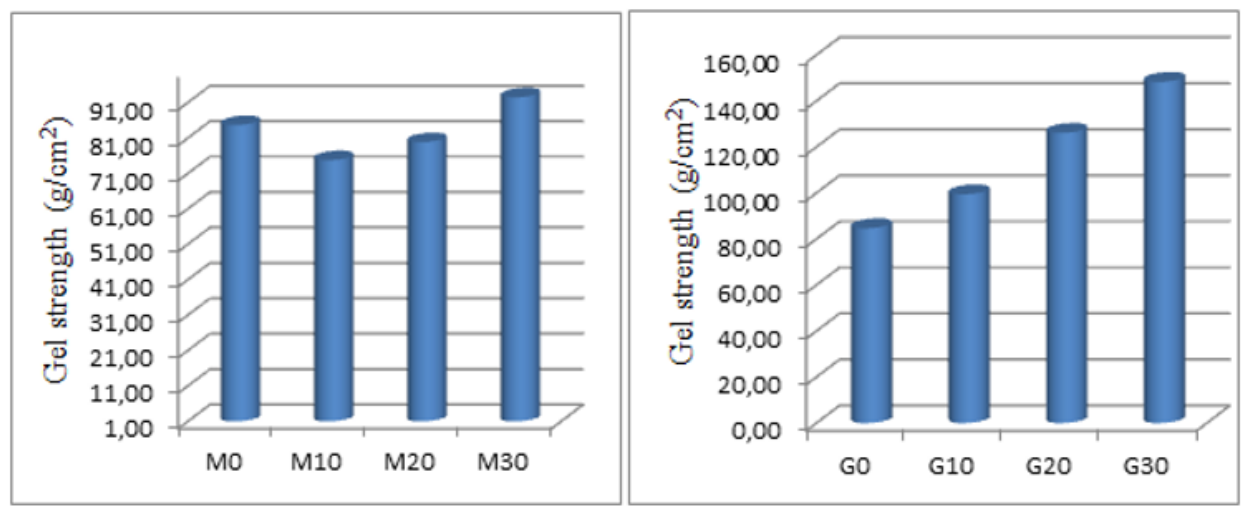

Fig. 2. Gel strength of alginate modified with polymannuronate and polyguluronate

Modulus rigidity of alginate gels modified by the addition of polymannuronate and polyguluronate were presented in Figure 3. The data showed that the modifications with the addition of polymannuronat gives little effect on changing the modulus rigidity of alginate gel. While it looks that the modifications with the addition of polyguluronat significantly increase modulus rigidity of alginate gel. The higher polyguluronate added, the higher modulus rigidity of alginate gel obtained. Increasing modulus rigidity by the addition of polyguluronate was caused by polyguluronate will enhance the ability of alginate to crosslinked with $\mathrm{Ca}^{2+}$ ions. The high guluronic blocks exist in alginate polymers caused the interaction with $\mathrm{Ca}^{2+}$ ions was high. The regional bloc of guluronic was an area that provides negative charge thus allowing binding of $\mathrm{Ca}^{2+}$ to produce a junction area (junction zone) for the creation of interactions between alginate molecules [7]. The more polyguluronat interact with ion $\mathrm{Ca}^{2+}$, the lower flexibility of the molecular movement and more rigid texture will be formed. 

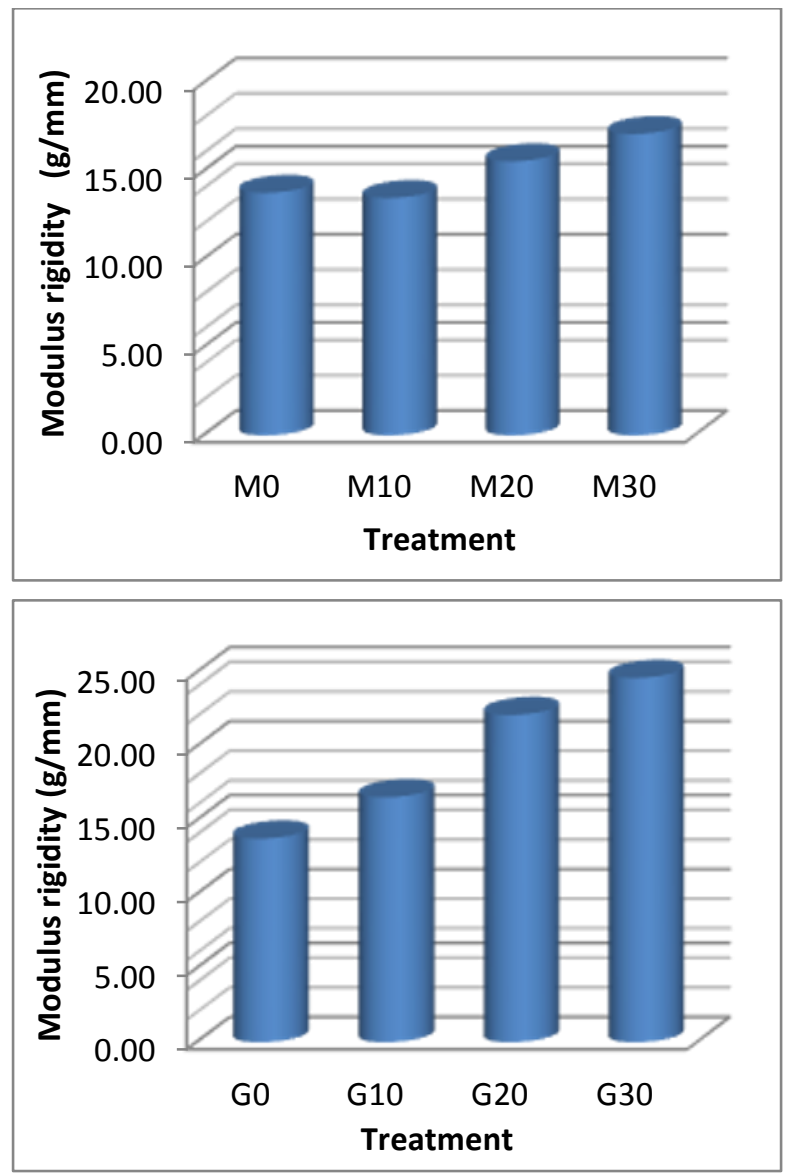

Fig. 3. Modulus rigidity of alginate gel modified by the addition of polymannuronate and polyguluronate

Observations syneresis of alginate gel modified with polymannuronete and polyguluronate presented in Table 2 . From these data it appears that modifications with the addition of polymannuronate has not significantly effect on alginate gel syneresis, while modification using polyguluronate has significantly effect. Modifications with the addition of polyguluronate tend to increase the value of alginate gel syneresis. The addition of polyguluronate increase alginate gel syneresis value due to more ability to bind $\mathrm{Ca}^{2+}$. Alginate rich content of guluronic blocks will produce egg-box model plentiful and with a high concentration of $\mathrm{Ca}^{2+}$ ions are then the electrostatic interaction higher. The higher the crosslinking are formed and the attractive force between molecules of the alginate higher, and in line with the increase in time, there will be shrinkage can cause the release of water from the gel or syneresis. 
Tabel 2. Syneresis of alginate gel modified with polymannuronete and polyguluronate

\begin{tabular}{|c|c|}
\hline Treatment & Syneresis (\%) \\
\hline Control & $5.03 \pm 0.38^{\mathrm{a}}$ \\
\hline M10\% & $5.25 \pm 0.57^{\mathrm{a}}$ \\
\hline M20\% & $5.28 \pm 0.55^{\mathrm{a}}$ \\
\hline M30\% & $5.26 \pm 0.51^{\mathrm{a}}$ \\
\hline G10\% & $7.43 \pm 0.60^{\mathrm{b}}$ \\
\hline G20\% & $6.39 \pm 0.57^{\mathrm{b}}$ \\
\hline G30\% & $7.30 \pm 0.02^{\mathrm{b}}$ \\
\hline
\end{tabular}

Note: values were expressed as mean \pm standard deviation

$\mathrm{M}=$ polymannuronate, $\mathrm{G}=$ polyguluronate

One of the important properties of alginate is its ability to form a gel and has been widely applied in the fields of biotechnology such as bacteria and enzyme immobilization. Alginate gel properties of heat resistance also causes this material widely used in the manufacture of various food products such as meat and fruit restructuring. Lately, alginate hydrogel applications are also widely used in the fields of pharmaceuticals for the manufacture of a controlled drug delivery system. To control the drug release system from gel can be made by modifying the molecular weight of alginate used [12]. To modify the rheological properties of alginate can be done with chitosan and multivalent electrolytes [13].

From this research noted that the addition of polymannuronate or polyguluronate to the native alginate will affect on the characteristics of the resulting gel. The more polymanuronate added, the stronger gel will be produced without reducing the value of syneresis. And conversely, the more polyguluronate addition will produce a higher gel, more rigid with higher syneresis value. Herefore, it is possible to produce alginate gel with the characteristics that that suitable for our needs. For example, to obtain an elastic alginate gel with low syneresis, we can add polymannuronate in an appropriate amounts. Instead, to produce a rigid alginate gel with high syneresis we can add polyguluronate on native alginate.

\section{Conclusion}

The addition of polimanuronat and polyguluronic had significant effect on the characteristics of alginate gel. The addition of polymannuronate tend to reduce the gel strength without changing in modulus rigidity of the gel. The addition of polyguluronate tends to improve gel strength and modulus of rigidity alginate gel. The addition of polymannuronate did not effect on alginate gel syneresis, while addition of polyguluronate tend to increase the value of syneresis.

\section{References}

1. A. Husni, Subaryono, Y. Pranoto, Tazwir and Ustadi. Agritech. 3, 1: 1-8 (2012)

2. Subaryono. Squalen 6, 2: 55-62 (2011)

3. Subaryono and R. Peranginangin, J. Mar. and Fish. Post. and Biotech. 4, 1: 131-140 (2009)

4. K.I. Draget, O. Smidsrøt, G. Skjåk-Braek. Alginat from Algae (Wiley-VCH Verlag GmbH \& co. KgaA. 2005) 
5. Subaryono, R. Peranginangin, D. Fardiaz, F. Kusnandar F. J. Pasca. dan Biotek. Kel. dan Perik. 5, 1: 43-55 (2010)

6. M.K. Simensen, K. Draget, F. Hjelland. Procedure for producing uronic acid blocks from alginate. US Patent 6,121,441(2000)

7. I. Ramsden, In Chemical and Functional Properties of Food Sachharides. (CRS Press LLC. p. 247-248, 2004)

8. K.I. Draget, K. Østgaard, O. Smidsrød. Carbohydrate Polymers. 14: 159-178 (1991)

9. Draget, K. I. 2000. Alginates. In Handbook of Hydrocolloids. (CRC Press. p. 379-395 2000)

10. W.M. Marrs, P. Titoria. In Gums and Stabilisers for the Food Industry 12. (The Royal Society of Chemistry. UK. p. 189-200 2004)

11. C.P. Reis, R.J. Neufeld, S. Vilela, A.J. Ribeiro, F. Veiga. J. Microencap. 23, 3: 245-257 (2006)

12. P. Sriamornsak, S. Sungthongjeen. AAPS Pharm Sci Tech 8, 3: 1-8 (2007)

13. B. Abu-Jdayil, D. Abu-Fara. Italian J. of Food Scie. 25,1:196-201 (2013)

14. Subaryono, R. Peranginangin, D. Fardiaz, F. Kusnandar. Aginate gel formation extracted from Sargassum filpendula and Turbinaria decurens with $\mathrm{CaCO}_{3}$ and glucono delta lactone. J. of Mar. and Fish. Post. and Biotechnol. 5, 1: 43-55 (2010) 